\title{
ESTRATÉGIAS DE PRODUÇÃO DE RESUMOS ACADÊMICOS
}

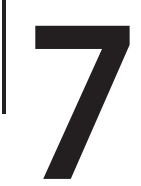

\section{STRATEGIES FOR THE PRODUCTION OF ACADEMIC ABSTRACTS}

\section{COSTA FILHO, Roberto Barbosa}

Graduando em Letras: Língua Portuguesa pela Universidade Federal de Campina Grande (UFCG).

Bolsista do Programa Institucional de Bolsas de Iniciação Científica (PIBIC/UFCG).

E-mail: costafrob@gmail.com

ORCID ID: https://orcid.org/0000-0003-3339-0124

\section{RODRIGUES, Márcia Candeia}

Doutora em Estudos Linguísticos Aplicados pela Universidade Federal de Pernambuco (UFPE)/

Universidade Nova Lisboa (UNL).

Professora adjunta da Universidade Federal de Campina Grande (UFCG).

E-mail:marciac_rodrigues@hotmail.com

ORCID ID: https://orcid.org/0000-0002-0932-3418

\section{RESUMO:}

No ensino superior, a escrita decorre da participação dos membros que compõem essa comunidade em práticas e eventos de letramentos acadêmicos (LEA; STREET, 1998; 2014) através da produção de textos de gêneros específicos. O resumo acadêmico é um exemplo desses gêneros. Embora esse texto tenha, em geral, uma orientação institucional para sua elaboração, observamos que ele apresenta diferenças particulares no tocante a sua escrita. Neste artigo, temos por objetivo analisar resumos acadêmicos produzidos por graduandos e publicados na Revista Ao Pé da Letra. Nesses resumos, descrevemos sua estrutura composicional face às orientações do periódico, verificando o que há de maior ou menor regularidade, em termos de estratégias de escrita utilizadas para organizar essa estrutura. Ao longo da análise, apoiamo-nos também na descrição de movimentos retóricos.

Palavras-chave: Resumo acadêmico. Escrita acadêmica. Estratégias de escrita.

\section{ABSTRACT:}

In higher education, writing results from the participation of members who make this community in academic literacy practices and events (LEA; STREET, 1998; 2014) through specific text genres 
production . Abstracts are an example of those genres. Although this text has, in general, an institutional orientation for its elaboration, we observe that it presents particular differences regarding its writing. Along this paper, we aim at analyzing academic abstracts produced by undergraduate students and published in the Academic Journal Ao Pé da Letra. In the abstracts, we describe their compositional structure in relation to the journal's guidelines. For that, we verify what is more or less regular, in terms of writing strategies used to organize such a structure. Throughout the analysis, we also rely on the description of rhetorical movements.

Keywords: Abstract. Academic writing. Writing strategies.

\section{INTRODUÇÃO}

As práticas de escrita no ensino superior decorrem da necessidade histórica de divulgação dos conhecimentos produzidos nesse espaço, como forma de manter as discussões científicas sobre questões de diversas ordens e propagar os resultados de pesquisas obtidos para benefício da sociedade. Nesse contexto, há a produção de textos de gêneros textuais específicos da academia, tais como o resumo acadêmico e o artigo científico, que atendem a propósitos comunicativos especializados de seus autores e da área em que estes se inserem. Os gêneros, assim, não são apenas categorias linguísticas estruturadas por meio de traços textuais definidos, mas categorias sociopsicológicas utilizadas e reconhecidas no estabelecimento e na construção de ações específicas (BAZERMAN, 2006).

Diversos estudos (IVANIČ, 2004; MACHADO; LOUSADA; ABREU-TARDELLI, 2004; MOTTA-ROT; HENDGES, 2010; RUSSEL, 2009; RODRIGUES, 2012, 2014, 2015, 2016 e 2017) já demonstram que a escrita na academia, e consequentemente o uso dos gêneros textuais típicos desse ambiente, recai determinantemente sob as práticas de letramentos acadêmicos (LEA; STREET, 1998; 2014) que constituem as experiências dos membros dessas comunidades. Visto dessa forma, a escrita demanda a necessidade de que esses membros reconheçam, respectivamente, que alguns textos cumprem propósitos definidos e que isso pode caracterizar o que eles vivenciam na própria academia ou vivenciarão na profissão futura.

Como lembram Fischer e Dionísio (2011), os textos produzidos no ensino superior são disciplinarmente especializados e situados, ou seja, 
as várias comunidades discursivas que constituem o ambiente acadêmico possuem normas e convenções próprias no que se refere à produção do conhecimento, o que resulta na variação linguística dos textos de acordo com as finalidades e o contexto de produção (BAZERMAN, $2006^{1}$ apud FISCHER; DIONÍSIO, 2011). Além disso, enquanto natureza institucional, o conhecimento produzido na academia se ancora nas relações entre a produção de sentido, identidade, poder e autoridade (LEA; STREET, 1998; 2014).

No entanto, por bastante tempo, a produção de textos acadêmicos ficou restrita a orientações de disciplinas como Metodologia do Trabalho Científico e, por conseguinte, das normas da Associação Brasileira de Normas Técnicas (ABNT) e dos materiais didáticos representativos da área (SEVERINO, 2007; MARCONI; LAKATOS, 2009, entre outros). Essas orientações, na maioria das vezes, restringem-se a ensinar e aprender conceitual e estruturalmente os principais textos científicos por meio de uma concepção generalizante, de modo a encarar os textos como resultados das mesmas exigências, sendo necessário seguir à risca tais orientações como um modelo a ser reproduzido e higienizado em termos de adequação ortográfica e linguística, o que não demonstra o atendimento às necessidades atuais de se escrever cientificamente.

Nessa interface, a pesquisa sobre a escrita de alunos de graduação possibilita a compreensão sobre os processos de produção textual, de modo a ampliar os entendimentos reais e situados sobre as organizações textuais dos gêneros utilizados. Os primeiros exercícios de divulgação científica na graduação geralmente ocorrem na iniciação científica, quando o aluno, orientado de forma regular e gradual, desenvolve um projeto de pesquisa ao longo de dois semestres. Como resultado desse processo, esse aluno produz textos acadêmicos que são submetidos à avaliação de bancas, além da divulgação dos resultados obtidos em outros eventos científicos. Para cada um desses momentos, são solicitados gêneros textuais específicos que podem ser submetidos para publicação on-line nas páginas de Instituições ou em periódicos científicos.

Nesse sentido, oresumoacadêmicoéum gênero textual amplamente utilizado. Em muitas situações, é o texto de apresentação para publicações científicas e participação desses membros em eventos da área. Com isso, esse texto oportuniza a circulação científica, dá visibilidade a diferentes tipos de pesquisa e consolida uma prática acadêmica decisiva para a

$\overline{\text { BAZERMAN }}, \mathrm{C}$. Atos de fala, gêneros textuais e sistemas de atividades: como os textos organizam atividades e pessoas. In: Dionísio, A.; Hoffnagel, J. C. (org.). Gêneros textuais, tipificação e interação. São Paulo: Cortez Editora, 2006. p. 19-46. 
ciência. Ao encabeçar artigos científicos, o resumo tem a função de convidar o leitor à leitura do texto integral e estabelece estrita relação com o texto do qual se origina - o artigo científico. No trabalho em questão, temos por objetivo analisar resumos acadêmicos produzidos por alunos de graduação e publicados em período científico. Nesses resumos, descrevemos sua estrutura composicional face às orientações do periódico destinadas aos autores, apoiando-nos também na descrição de movimentos retóricos. Além disso, identificamos as estratégias de escrita utilizadas para a produção desse texto.

Dessa forma, esta pesquisa se justifica por contribuir para o desenvolvimento de uma pedagogia sobre a escrita e sobre a produção de resumos acadêmicos e, por consequência, sobre o funcionamento dos letramentos acadêmicos. Destacamos a relevância do problema focalizado no contexto da Linguística Textual e Aplicada e sua importância para desenvolvimento de metodologias e materiais didáticos destinados ao ensino da escrita na academia. Ampliar essa discussão é, pois, fundamental para consolidação de uma pedagogia da escrita, para compreensão e descrição de práticas que podem ajudar o aluno a desempenhar satisfatoriamente a tarefa de produzir textos comuns à comunidade da qual faz parte.

\section{ASPECTOS METODOLÓGICOS}

Este trabalho apresenta partes dos resultados obtidos pela pesquisa Do artigo científico ao resumo acadêmico: a produção escrita em periódicos da UFCG (PIVIC/UFCG 2018-2019). O projeto está vinculado ao grupo de pesquisa Teorias da Linguagem e Ensino e à linha Língua(gem) em Contexto de Ensino de Português (LM), do curso de Letras da Universidade Federal de Campina Grande (UFCG). No conjunto de objetos investigados nessa linha, destaca-se a escrita, mais especificamente, seu ensino e os processos que caracterizam sua didatização em contextos institucionalizados ou não, bem como descrição e análise de unidades linguísticas em uso.

Dessa forma, utilizamos procedimentos típicos do paradigma qualitativo e interpretativo de pesquisa. Neste paradigma, a pesquisa se destaca como um método promissor de estudo para as ciências humanas e sociais, e não subtrai o fenômeno a ser estudado de seu contexto, isto é, dos modos de organização das comunidades nas quais está inserido. (CHIZZOTTI, 2003).

Pela natureza de nossos dados, caracteriza-se como documental. Neste tipo de pesquisa, examinam-se documentos - no nosso caso, 
textos escritos - para extrair informações contidas neles para obter novas interpretações e/ou complementar interpretações existentes sobre determinado fenômeno. Por isso, propõe-se a produzir novos conhecimentos, de modo a possibilitar novas formas para compreensão de fenômenos. (GODOY, 1995; SÁ-SILVA; ALMEIDA; GUINDANI, 2009; KRIPKA; SCHELLER; BONOTTO, 2015).

Para tanto, o corpus de análise constitui-se de sete resumos acadêmicos, componentes de seus respectivos artigos científicos, publicados na Revista Ao Pé da Letra, do Departamento de Letras da Universidade Federal de Pernambuco (UFPE), extraídos de volumes entre 2014 e 2017. Esses textos possuem autoria declarada do aluno de graduação, com aval de um professor (mestre ou doutor) na posição de orientador - e não de coautor $^{2}$. Esses textos ainda são representativos de diversidade programas e/ou disciplina curricular ${ }^{3}$ a que alunos de graduação participam.

O RESUMO ACADÊMICO NAS PRÁTICAS DE LETRAMENTOS ACADÊMI-

\section{$\cos$}

São diversos os estudos que discutem concepções, representações e estratégias de escrita do texto do resumo acadêmico. Guimarães Silva e Mata (2002, p. 124) verificaram que "os resumos, vistos como gênero, são práticas de produção de linguagem, produzidas e consumidas para atender a diversas necessidades sociocomunicativas". No cenário acadêmico, o resumo de tese ou de dissertação, abstract, resumo de trabalhos para Congressos e resumo escolar são alguns exemplos dos propósitos do gênero, conforme necessidade comunicativa do produtor.

Ao explorar como alunos de Letras no ensino superior concebem esse gênero textual, Assis, Mata e Perini-Santos (2003) verificaram as seguintes representações:

(i) apenas cópia de trechos do texto-base, obedecendo à sequência deste; (ii) seleção de ideias representativas de cada parágrafo do texto-base, na ordem em que nele aparecem, sem estabelecimento de vínculo explícito entre

\footnotetext{
É válido ressaltar que não temos a pretensão, nesta pesquisa, de diferenciar e/ou questionar os papéis de coautor e orientador na produção escrita de um texto acadêmico. Todavia, em concordância com os objetivos estabelecidos, faz-se necessário termos como corpus de análise textos cuja autoria seja, declaradamente, de graduandos.

3 Os textos são oriundos de pesquisas vinculadas aos programas: Programa Institucional de Bolsas de Iniciação Científica (PIBIC/CNPq), Programa Institucional de Bolsas de Iniciação à Docência (PIBID/Capes), Programa de Educação Tutorial (PET), Programa de Iniciação Científica (PROBIC/FAPERGS) e Iniciação Científica financiada pela Fundação de Amparo à Pesquisa do Estado da Bahia (FAPESB) e pela Fundação de Amparo à Pesquisa do Estado do Rio Grande do Sul (FAPERGS); também à disciplina Estágio Curricular Supervisionado de Língua Portuguesa e Literatura.
} 
elas; (iii) apresentação da macroproposição do textobase, considerados os objetivos do mesmo (nesse caso, observou-se a tentativa de articular as proposições centrais do texto), seguida de comentários em que se extrapolava e até mesmo se contradizia o texto-base em muitos de seus aspectos; (iv) comentários sobre aspectos sugeridos pela temática do texto-base. (ASSIS; MATA; PERINI-SANTOS, 2003, p. 02).

Essas representações são advindas do processo escolar em que esses alunos se inseriram ao longo de toda a educação básica. Nessa fase, vale ressaltar, a produção de resumos centra-se, principalmente, na avaliação e registro escrito da leitura, como forma de controle (ASSIS; MATA; PERINI-SANTOS, 2003; GUIMARÃES SILVA; MATA, 2002). Desse modo, as práticas em que o resumo aparece são construídas por meio de recortes do texto-base, com cópia de trechos, ou somente com a tematização da ideia central.

As experiências adquiridas ao longo da vida escolar ainda conferem a esses alunos visões que, de acordo com as autoras, são construídas por meio de uma noção relacional de que a simplificação do texto-fonte é realizada através da seleção das ideias principais, com fidelidade aos pensamentos do autor. Isso, em geral, não nos permite conferir até que ponto há, nesses alunos, a observância de uma estrutura prototípica para o texto do gênero resumo, nem a funcionalidade comunicativa desempenhada por ele.

Por outro lado, o resumo nas práticas acadêmicas, segundo Guimarães Silva e Mata (2002), caracteriza-se como decorrência de atividades de retextualização de outros gêneros textuais que circulam nessa esfera, como artigos ou capítulos de livros, o que demanda a efetuação de operações mentais para a compreensão do texto-base. Além disso, ressaltam as autoras, é imprescindível diferenciar "o processo de sumarização (operações mentais) que ocorre durante o processamento de um texto em situação de leitura com o texto-resumo produzido pelo processo de retextualização" (GUIMARÃES SILVA; MATA, 2002, p. 126). Essa ressalva torna-se essencial para firmar que, enquanto gênero textual, o resumo possui uma estrutura retórico-composicional, relativamente estável, que possibilita a sua identificação.

Especificando o resumo acadêmico (ou abstract), este tem por objetivo "sumarizar, indicar e predizer, em um parágrafo curto, o conteúdo e a estrutura do texto integral que segue" (MOTTA-ROTH, 
HENDES, 2010, p. 152). De modo geral, esse tipo de resumo apresenta, de acordo com Motta-Roth e Hendges (2010), uma informação precisa e completa, tendo a missão de persuadir o leitor a ler o artigo completo, com destaque para a relevância e pertinência de resultados. Retoricamente, o resumo acadêmico se comporta de modo a refletir tanto o conteúdo quanto a estrutura do trabalho.

A partir da análise de sessenta resumos, Motta-Roth e Hendges (2010) apresentam uma descrição esquemática dos movimentos retóricos possíveis de serem encontrados em um resumo acadêmico:

Quadro 1: Descrição esquemática de abstracts (Motta-Roth, Hendges, 1996, p. 68, com base em Bittencourt, 1995, p. 485)

\begin{tabular}{lc}
\hline MOVIMENTO 1 - SITUAR A PESQUISA & ou \\
Subfunção 1A - Estabelecer interesse profissional no tópico & e/ou \\
Subfunção 1B - Fazer generalizações do tópico & ou \\
Subfunção 2A - Citar pesquisas prévias & ou \\
Subfunção 2B - Estender pesquisas prévias & ou \\
Subfunção 2C - Contra-argumentar pesquisas prévias & \\
Subfunção 2D - Indicar lacunas em pesquisas prévias & \\
MOVIMENTO 2 - APRESENTAR A PESQUISA & ou \\
Subfunção 1A - Indicar as principais características & e/ou \\
Subfunção 1B - Apresentar os principais objetivos & \\
Subfunção 2 - Levantar hipóteses & \\
MOVIMENTO 3 - DESCREVER A METODOLOGIA & \\
MOVIMENTO 4 - SUMARIZAR OS RESULTADOS & \\
MOVIMENTO 5 - DISCUTIR A PESQUISA & e/ou \\
Subfunção 1 - Elaborar conclusões & \\
Subfunção 2 - Recomendar futuras aplicações &
\end{tabular}

Fonte: Motta-Roth; Hendges (2010, p. 155).

Esses movimentos são identificados, na maioria dos casos, por meio de marcadores metadiscursivos (MOTTA-ROTH; HENDGES, 2010), ou seja, itens lexicais caracterizadores das informações que constituem as diversas seções do artigo, já que o resumo tem relação estrita com esse texto, o que ocasiona um campo semântico relativamente controlado. Linguisticamente, conforme as autoras, os verbos usados no resumo são conjugados, principalmente, na terceira pessoa do singular do pretérito composto e do presente do indicativo, na voz passiva, além de uma linguagem econômica com sentenças simples e declarativas.

De modo sucinto, a Norma Brasileira (NBR) 6028:2003 estabelece que esse texto se constitui de objetivo, método, resultado e conclusão, 
além do indicativo de que a primeira frase seja significativa ${ }^{4}$. Indica que esse texto deve ser composto de uma sequência de frases concisas e afirmativas, preferencialmente em parágrafo único, com uso da voz ativa e da terceira pessoa do singular. Do artigo, em geral, o resumo privilegia o que está em seu(s) objetivo(s) e sua estrutura composicional.

Uma vez que a escrita e outros objetos são aprendidos, as preocupações teóricas têm recaído, de acordo com Boruchovith (1999), sobre o modo como o aprendiz interage com esses objetos e, em particular, sobre o modo como ele obtém, seleciona, interpreta e transforma a(s) informação(ões). Esse fato tem sugerido que é possível ajudar os alunos a exercer mais controle e reflexão sobre seu próprio processo de aprendizagem, através do ensino de estratégias de aprendizagem (BORUCHOVITH, 1999).

As estratégias de aprendizagem são concebidas como procedimentos, operações e escolhas de natureza de várias ordens, que são responsáveis tanto por uma aprendizagem efetiva quanto por uma autorregulação da ação de aprender. São um conjunto de ações ordenadas e finalizadas, isto é, dirigidas à consecução de uma meta. Vistas como procedimentos, o uso e a seleção de certas estratégias indicam, a partir de sua frequência, uma regra, técnica, método, destreza ou habilidade do aluno para realizar uma tarefa.

No conjunto de estratégias de aprendizagem de escrita suscitadas pelo próprio termo, reconhecemos que alunos e professores de língua portuguesa identificam, de forma muito discreta e incipiente, como adotá-las, ativá-las ou até adequá-las aos objetivos traçados/pretendidos. Enquanto operações, procedimentos ou técnicas (MATLIN, 2004; FIGUEIRA, 2006), as estratégias de escrita podem caracterizar o que se tem denominado como pedagogia da escrita.

\section{ANÁLISE DOS DADOS}

Ao iniciarmos a análise do corpus selecionado, apresentamos as orientações dispostas nas Diretrizes para autores da Revista Ao Pé da Letra para a produção do artigo científico, a fim de observar as instruções as quais os autores dos textos tinham disponíveis para guiar o processo de produção escrita. Vejamos:

DIRETRIZES GERAIS: IDIOMAS, LAUDAS (Artigos e ensaios: entre 10 e 20 laudas); LAYOUT DAS 


\section{LAUDAS; NORMAS DE FORMATAÇÃO:}

Título, Autor, Resumo: Obrigatório apenas para artigo, na língua em que tiver sido escrito e um na língua estrangeira (uma das línguas da revista). Colocado duas linhas abaixo do nome do autor, estilo Times New Roman, corpo 11, espaço simples, justificado. O resumo deve obrigatoriamente conter os seguintes elementos: objetivo do estudo, aporte teórico, metodologia adotada, síntese dos resultados. Pode ter no mínimo 100 e no máximo 250 palavras. Palavras-chave, Fonte, Tópicos e subtópicos, Imagens, tabelas, quadros ou gráficos, Notas de rodapé, Referências no corpo do texto, Citações e Referências. ${ }^{5}$

Essas orientações, no que especialmente nos interessa, demonstram que o texto do resumo possui uma extensão limitada, entre 100 e 250 palavras, além de apresentar elementos obrigatórios a aparecem nesse texto: objetivo do estudo, aporte teórico, metodologia adotada, síntese dos resultados. Essas orientações pressupõem a produção de um texto curto, que sintetize as informações apresentadas no artigo de que integra, com similaridade aos elementos propostos pela NBR 6028:2003, a exceção do acréscimo do aporte teórico.

Diante disso, observemos um exemplo de resumo publicado:

\section{Exemplo 1 - Resumo Andrade $(2017)^{6}$}

Objetiva-se analisar se a oralidade e a gramática normativa são desenvolvidas no livro didático do $7^{\circ}$ ano, visando à competência discursiva do aluno; como específico, verificar se há uma diversidade de gêneros orais no LD. Utilizamos como referencial teórico, Marcuschi (2008), PCNs (1998), Antunes (2003), Travaglia (2001), entre outros. A metodologia é qualitativa e quantitativa. Constata-se que a oralidade é explorada. Os aspectos gramaticais são contextualizados, colaborando com a reflexão crítica do aluno, contemplando, nos capítulos, situações formais e informais da língua. Dessa forma, as atividades, frequentemente, perpassam pela leitura, interpretação, produção textual, propiciando uma aprendizagem significativa para o aluno.

Neste exemplo, verificamos que a autora inicia o resumo com o uso da indeterminação do sujeito para demarcar, explicitamente, o objetivo do presente trabalho, por meio do verbo objetivar na $3^{\text {a }}$ pessoa do singular do presente do indicativo juntamente com a partícula

\footnotetext{
$5 \quad$ Fragmentado. Disponível em:

https://periodicos.ufpe.br/revistas/pedaletra/about/ submissions\#authorGuidelines. Acesso em: 23 abr. 2019.

6 ANDRADE, N. P. Oralidade e gramática no livro didático do $7^{\circ}$ ano. Revista ao Pé da Letra. v.19.1, 2017, p. 31-51.
} 
apassivadora se. Além disso, ao demarcar um segundo objetivo, utiliza o adjetivo específico, tendo o substantivo objetivo subtendido no trecho.

No período seguinte, a autora passa a utilizar a $1^{\text {a }}$ pessoa do plural, a partir do verbo utilizar flexionado no presente ou no pretérito perfeito do indicativo. Neste caso, a autora passa a anunciar a teoria a qual se ancora, declaradamente demonstrada pelos autores citados e pelo sintagma nominal aporte teórico. A metodologia, de forma também explícita, é expressa em frase declarativa, com a utilização de sintagma nominal com a própria denominação e com a classificação tipológica da pesquisa.

A partir de três períodos, a autora apresenta os resultados do estudo. Inicialmente, faz uso, novamente, da indeterminação do sujeito, através do verbo constatar flexionado na $3^{\text {a }}$ pessoa do presente do indicativo seguido de oração subordinada substantiva objetiva direta. A utilização do verbo constatar demonstra explicitamente o resultado, considerando-se o valor semântico que ele carrega ${ }^{7}$. Os dois períodos seguintes, claramente, visam justificar o resultado obtido e anunciado anteriormente, com explicação para a constatação chegada; são ambos períodos compostos, com a segunda oração sendo iniciadas com verbo no gerúndio, o que reforça uma ideia de continuidade da ação no futuro.

Com isso, percebe-se que o resumo atendeu a todos os elementos indicados como obrigatórios pela norma da Revista, com a quantidade mínima de palavras (100 palavras). Esses elementos, que representam movimentos retóricos de apresentar a pesquisa, por meio da apresentação dos principais objetivos, de descrever a metodologia e de sumarizar os resultados, são elaborados por sua autora de modo explícito através do uso de verbos e de marcadores metadiscursivos característicos, o que facilita a interpretação do leitor.

Entretanto, em outros casos, alguns desses elementos aparecem por meio de construções textuais implícitas. Vejamos mais um exemplo: 


\title{
Exemplo 2 - Resumo Tondini $(2017)^{8}$
}

\begin{abstract}
Este artigo analisa a abordagem da produção textual no livro didático Linguagens, do $6 .^{\circ}$ ano do Ensino Fundamental II, e se essa abordagem vai ao encontro do que prescrevem os Parâmetros Curriculares Nacionais (1998), as Diretrizes Curriculares da Educação Básica (2008) e autores como Marcuschi (2002), Dolz e Schneuwly (2004), Fiorin (2006) e Antunes (2006). Realizou-se, no ivro didático analisado, em cada unidade, um levantamento dos gêneros textuais contemplados pela eitura e produção textual e seus respectivos encaminhamentos metodológicos. Essa análise eforçou a importância de se estudar os gêneros textuais no ensino da língua portuguesa, tornando-o ignificativo.
\end{abstract}

Neste caso, ao iniciar também com a apresentação dos objetivos ${ }^{9}$, o autor utiliza uma estratégia de escrita implícita, uma vez que faz uso do sintagma nominal Este artigo que, de certa forma, indetermina o realizador da ação verbal, acompanhado do verbo analisar ${ }^{10}$, flexionado no $3^{a}$ pessoa do singular do presente do indicativo. Esse verbo é recorrentemente utilizado para demarcar uma ação a ser realizada em textos acadêmicos, pelo valor semântico que apresenta, comum ao ato de pesquisar.

Os autores que são considerados como aportes teóricos são atrelados aos objetivos, visto que são considerados também como aportes analíticos no sentido comparativo entre o corpus de análise e o que é apresentado pelos autores e documentos citados. Dessa forma, são identificados por meio da própria citação realizada a eles.

No caso da descrição metodológica, diferentemente do que é realizado no resumo anterior, este não realiza a classificação tipológica da pesquisa, mas apresenta o que fora realizado como movimento de análise. Nesse sentido, o autor faz uso de uma construção sintática de indeterminação do sujeito, com o uso do verbo realizar flexionado na $3^{a}$ pessoa do singular do pretérito perfeito do indicativo acompanhado da partícula apassivadora se. O tempo verbal, comum em trechos que marcam passos metodológicos, indica a já conclusão da ação, pressupondo o término da pesquisa.

Por fim, o autor apresenta conclusões para esse estudo, elemento não apresentado como obrigatório pelas normas da Revista, mas considerado pela NBR 6028:2003 e utilizado como movimento de discussão da pesquisa. Para isso, repete a estratégia de utilizar um sintagma nominal (Essa análise) que não indica um realizador humano

8 TONDINI, D. P. A produção de textos no Livro Didático de Língua Portuguesa do $6^{\circ}$ ano do Ensino Fundamental. Revista ao Pé da Letra. v.19.2, 2017, p. 1-19.

9 A abertura do resumo se dá com a apresentação dos objetivos em 5 dos resumos analisados, sendo o movimento retórico que aparece em todos os textos.

$10 \quad$ Esse verbo aparece em 5 dos textos analisados. 
para a ação. O verbo utilizado é reforçar, que possui um valor semântico de "tornar mais forte" uma ideia já considerada pela área, em comparação a estudos já realizados.

Com essa análise, percebe-se que, além do acréscimo já mencionado, o autor não apresenta no texto os resultados obtidos, elemento considerado obrigatório pelas orientações para autores. De mesmo modo, o texto apresenta 97 palavras, número inferior ao mínimo indicado pela Revista. Com isso, verifica-se que especialidades outras, além das normas institucionalizadas, são consideradas na produção de um texto, a fim de atender aos propósitos comunicativos desejados.

Observemos mais um exemplo:

Exemplo 3 - Resumo Silva $(2014)^{11 \mathrm{~m}}$

Este artigo tem o objetivo de analisar como os livros didáticos de língua portuguesa da coleção Língua portuguesa: Linguagem e interação, de Faraco, Moura e Maruxo Júnior (2010), utilizados em escola de Ensino Médio do município de Redenção-CE, abordam o fenômeno da variação linguística. Partimos do pressuposto de que as emissões de preconceito a determinadas variedades decorrem principalmente da falta de conhecimento sobre esse fenômeno, portanto entendê-lo é ferramenta de combate a esse tipo de preconceito. Para tanto, os fundamentos teóricos utilizados foram baseados principalmente nos estudos de Alkmim (2012), Bagno (2011), Travaglia (2009), com discussões sobre as relações entre variação, ensino e materiais didáticos. Os resultados mostram que a abordagem da variação no livro didático ainda é bastante superficial, apresentando algumas falhas.

Similar ao que foi observado no texto anterior, neste o autor também inicia o seu resumo com a apresentação de seu objetivo, utilizando uma oração com o sintagma nominal Este artigo, que não demonstra o realizador humano da ação verbal. Explicitamente, podemos verificar que se trata do objetivo pelo uso do sintagma nominal o objetivo, em posição de objeto direto. Os verbos utilizados, nesse primeiro período, são ter, flexionado na $3^{a}$ pessoa do singular do presente do indicativo, analisar, no infinito, para marcar a ação que se deseja realizar com a pesquisa, e abordar, na $3^{a}$ pessoa do plural do presente do indicativo.

Em seguida, o autor utiliza-se de uma contextualização temática para indicar explicações necessárias para entendimento do que é pretendido, elemento não visionado pelas normas da Revista. Estamos entendendo que a contextualização temática, seja na abertura do texto, seja em seu interior, como neste caso, serve para orientar o leitor acerca de especificidades contempladas pelo trabalho, próprias da área de

11 SILVA, E. N. Variação linguística: das discussões acadêmicas aos livros didáticos. Revista ao Pé da Letra. v. 2016.2, 2014, p. 85-103. 
conhecimento em que se insere. Nesse exemplo, o autor utiliza um sujeito oculto, indicado pela flexão do verbo partir na $1^{\text {a }}$ pessoa do plural do presente ou do pretérito perfeito do indicativo.

O autor também apresenta o aporte teórico de sustentação do trabalho, indicado explicitamente e demarcado pelo marcador metadiscursivo fundamentos teóricos. Logo após, o autor apresenta os resultados atingidos, por meio de construção textual que não determina um realizador humano. Para isso, faz uso do sintagma nominal Os resultados, acompanhado do verbo mostrar, flexionado na $3^{\text {a }}$ pessoa do plural do presente do indicativo.

De modo geral, os resumos analisados demonstram:

Quadro 1 - Síntese dos movimentos retóricos dos resumos e estratégias de escrita adotadas

\begin{tabular}{|c|c|c|}
\hline $\begin{array}{l}\text { MOVIMENTO } \\
\text { RETÓRICO }\end{array}$ & $\begin{array}{l}\text { QUANTIDADE } \\
\text { DE EXEMPLOS }\end{array}$ & ESTRATÉGIA DE ESCRITA \\
\hline $\begin{array}{l}\text { Apresentação } \\
\text { dos objetivos }\end{array}$ & Em 7 resumos & $\begin{array}{l}\text { Ora são apresentados explicitamente, por meio do uso do } \\
\text { substantivo objetivo(s) ou do verbo objetivar, ora de forma } \\
\text { implicita, através do uso de verbos como apresentar, } \\
\text { discutir, analisar e propor. Correntemente, são utilizadas } \\
\text { construções textuais com sintagmas nominais que } \\
\text { indeterminam um realizador humano para a ação, como } \\
\text { este artigo. }\end{array}$ \\
\hline $\begin{array}{l}\text { Anúncio de } \\
\text { aporte teórico }\end{array}$ & Em 7 resumos & $\begin{array}{l}\text { O aporte teórico é sempre identificado por meio da citação } \\
\text { de autores, seguido de data da obra entre parênteses. } \\
\text { Textualmente, pode apresentar o sintagma nominal } \\
\text { referencial (is) fundamento(s) teórico(s) e/ou verbos como } \\
\text { apropriar, fundamentar e utilizar. }\end{array}$ \\
\hline $\begin{array}{l}\text { Descrição de } \\
\text { metodologia }\end{array}$ & Em 5 resumos & $\begin{array}{l}\text { A metodologia apresenta-se seja com a classificação } \\
\text { tipológica da pesquisa, iniciada por sintagma nominal com } \\
\text { o substantivo metodologia, seja através da descrição de } \\
\text { ações realizadas, com a utilização de verbos como realizar } \\
\text { conjugados no pretérito perfeito. }\end{array}$ \\
\hline $\begin{array}{l}\text { Sumarização de } \\
\text { resultados }\end{array}$ & Em 3 resumos & $\begin{array}{l}\text { Os resultados aparecem com o uso de sintagma nominal } \\
\text { com o substantivo resultado(s) ou por meio de períodos } \\
\text { compostos que, por meio de seu conteúdo, demonstram } \\
\text { sumarizar as respostas atingidas pelas pesquisas, com } \\
\text { verbos conjugados no presente, no pretérito perfeito do } \\
\text { indicativo e no genúndio. }\end{array}$ \\
\hline $\begin{array}{l}\text { Elaboração de } \\
\text { conclusões }\end{array}$ & Em 2 resumos & $\begin{array}{l}\text { Expressamente demarcada pelo uso do substantivo } \\
\text { conclusão(des) ou de verbos como reforçar com valores } \\
\text { semânticos realizados a sustentação, confirmação de ideias } \\
\text { na área. }\end{array}$ \\
\hline $\begin{array}{l}\text { Construção de } \\
\text { contextualização } \\
\text { temática }\end{array}$ & Em 2 resumos & $\begin{array}{l}\text { São periodos com conteúdo relacionado à área temática do } \\
\text { trabalho, de modo a auxiliar na delimitação do que se } \\
\text { deseja realizar na pesquisa. Por sua ligação à temática, o } \\
\text { modo de textualização desse movimento é variável, } \\
\text { aparecendo ora como primeiro, ora como segundo periodo } \\
\text { do texto. }\end{array}$ \\
\hline
\end{tabular}

Fonte: Elaborado pelos autores. 


\section{CONSIDERAÇÕES FINAIS}

Neste trabalho, analisamos sete textos do gênero resumo acadêmico escritos por alunos de graduação e publicados na Revista Ao Pé da Letra, de modo a identificar e analisar sua estrutura composicional, em consideração aos movimentos retóricos recorrentes nesse texto, e as estratégias de produção para elaboração textual dessa estrutura. Com isso, observamos que os movimentos retóricos mais recorrentes nesses textos são a apresentação dos objetivos e o anúncio do aporte teórico, presentes em todos os exemplares analisados. Esses movimentos, além de compuserem a norma da Revista como elementos obrigatórios, também são citados pela NBR 6028:2003.

Estrategicamente, esses movimentos são apresentados na escrita desses textos ora explicitamente demarcados por meio do uso de sintagmas nominais que constam o nome do elemento (substantivo resultado(s), por exemplo), ora com o uso de verbos com valores semânticos dentro do campo do elemento (como analisar ou propor para o objetivo). Outra estratégia que chama atenção diz respeito à indeterminação de um realizador humano para a ação desempenhada pelo verbo, sendo atribuídos sintagmas nominais como este artigo ou essa análise como sujeitos da oração ou mesmo com o uso da indeterminação do sujeito com acréscimo da partícula apassivadora se, que pode ser justificada pela tradição científica de produção de textos com distanciamento dos pesquisadores, com uso da $3^{\text {a }}$ pessoa.

Além disso, em comparação às orientações para autores destinadas pela Revista, dois resumos analisados não atendem ao número mínimo de palavras definido, e mesmo assim foram publicados. De mesmo modo, cinco desses textos não contemplam, ao menos, um dos elementos tidos como obrigatórios para o resumo, especialmente a apresentação de resultados. Também observamos que quatro desses textos acrescentam elementos não contemplados pelas orientações, a saber: a contextualização temática e a conclusão. Com isso, percebemos que as normas da Revista não são consideradas como "amarras" para (não) aceitação de um texto a ser publicado. Isso demonstra que outras práticas de escrita são consideradas para a análise dos textos submetidos, considerando, certamente, as condições a que esses alunos são submetidos nas práticas e eventos dos letramentos acadêmicos. Reforça-se, assim, a ideia de especialidade e situacionalidade disciplinar dos textos produzidos na academia. 


\section{REFERÊNCIAS}

ASSIS, J. A.; MATA, M. A.; PERINI-SANTOS, P. Ensino/aprendizagem de resumos acadêmicos em sala de aula: negociação de representações. In: Anais do II Encontro Internacional Linguagem, Cultura e Cognição: Reflexões para o Ensino. Campinas, SP: Graf. FE; ALB, 2003.

ASSOCIAÇÃO BRASILEIRA DE NORMAS TÉCNICAS (ABNT). NBR 6028: informação e documentação - Resumo - Apresentação. Rio de Janeiro, 2003.

BAZERMAN, C. Gênero, agência e escrita. Organização: Judith Chambliss Hoffnagel, Angela Paiva Dionísio; tradução e adaptação: Judith Chambliss Hoffnagel. São Paulo: Cortez, 2006.

BORUCHOVITCH, E.; SANTOS, A. A. A. Estratégias de aprendizagem: conceituação e avaliação. In: A. P. P. NORONHA e F. F. SISTO (Orgs.). Facetas do fazer em avaliação psicológica (p. 107-124). São Paulo: Vetor, 2006.

BORUCHOVITCH, E. Estratégias de aprendizagem e desempenho escolar: considerações para a prática educacional. Psicologia: Reflexão e Crítica, 12, 361-376. 1999.

CHIZZOTTI, A. A pesquisa qualitativa em ciências humanas e sociais: evolução e desafios. Revista Portuguesa de Educação. Ano/vol. 16. N. 002. Universidade do Ninho. Braga, Portugal. 2003.

FERREIRA, A. B. H. Miniaurélio Século XXI Escolar. 4. ed. rev. ampliada. Rio de Janeiro: Nova Fronteira, 2001.

FIGUEIRA, Ana Paula. Estratégias cognitivo/comportamentais de aprendizagem. Problemática conceptual e outras rubricas. Revista Iberoamericana de Educación, 2006. Disponível em: http://www.rieoei.org/deloslectores/1130Couceiro.pdf. Acesso em: 15 dez. 2019.

FISCHER, A.; DIONÍSIO, M. L. Perspectivas sobre letramento(s) no ensino superior: objetos de estudo em pesquisas acadêmicas. Atos de Pesquisa em Educação, v. 6, n. 1, p. 79-93, jan/abr, 2011.

GODOY, A. S. Pesquisa qualitativa: tipos fundamentais. Revista de Administração de Empresas. São Paulo, v.35, n.3, p. 20-29, mai/jun., 1995.

GUIMARÃES SILVA, J. Q.; MATA, M. A. da. Proposta tipológica de resumos: um estudo exploratório das práticas de ensino da leitura e da produção de textos acadêmicos. Scripta, Belo Horizonte, v. 6, n. 11, p. 123-133, 2ºm. 2002.

IVANI $\check{C}, \mathrm{R}$. The discourses of writing and learning to write. Language and education, v.18,n.3, p. 220-245, 2004. 
KRIPKA, R. M.; SCHELLER, M.; BONOTTO, D. L. Pesquisa documental na pesquisa qualitativa: conceitos e caracterização. Revista de investigaciones. UNAD Bogotá Colombia. No. 14, julio-diciembre, p. 55-73.

LEA, M.R; STREET, B. Student writing in higher education: an academic literacies approach. Studies in Higher Education, v. 23, n. 2, p. 157-172, Jun. 1998.

LEA, M.; STREET, B. O modelo de "letramentos acadêmicos": teoria e aplicações. Revista Filologia e Linguística Portuguesa, São Paulo, v. 16, n. 2, p. 477-493, jul/dez, 2014.

MACHADO, A.; LOUSADA, E.; ABREU-TARDELLI, L. Resumo. São Paulo: Parábola, 2004.

MARCONI, M. A.; LAKATOS, E. M. Fundamentos da metodologia científica. 6. ed. São Paulo: Atlas, 2009.

MATLIN, Margareth. W. Psicologia Cognitiva. Trad. Stella Machado. 5 ed. Rio de Janeiro, RJ: LTC, 2004.

MOTTA-ROTH, D.; HENDGES, G. Produção textual na Universidade. São Paulo: Parábola Editorial, 2010.

RODRIGUES, M. C. Gêneros acadêmicos escritos: crenças e estratégias de aprendizagem. 2012. 331 f. Tese (doutorado em Letras) - Universidade Federal de Pernambuco, Centro de Artes e Comunicação, Programa de Pós-graduação em Letras. Recife, 2012.

RODRIGUES, M. C. Normalização e estratégias de escrita de textos no ensino superior. PIBIC 2014-2015. CNPQ/UFCG. 2014.

RODRIGUES, M. C. Normalização e estratégias de aprendizagem da produção escrita no ensino superior. PIBIC 2015-2016. CNPQ/UFCG. 2015.

RODRIGUES, M. C. Letramentos e práticas acadêmicas de publicação escrita na UFCG. PIBIC 2016-2017. CNPQ/UFCG. 2016.

RODRIGUES, M. C. Letramento acadêmico: práticas e estratégias de ensino da escrita. PIBIC 2017-2018. CNPQ/UFCG. 2017.

RUSSEL, D. In: RAMOS, F. B. (et al.). Letramento acadêmico: leitura e escrita na Universidade: entrevista com David Russel. Revista Conjuntura. V.14, n. 2, mai/ago. 2009. Disponível em: http://www.ucs.br/etc/revistas/index.php/conjectura/article/ viewFile/31/29. Acesso em: 15 set. 2011.

SÁ-SILVA, J. R.; ALMEIDA, C. D.; GUINDANI, J. F. Pesquisa documental: pistas teóricas e metodológicas. Revista Brasileira de História \& Ciências Sociais. Ano I - Número I Julho de 2009, p. 1-15.

SEVERINO, A. J. Metodologia do Trabalho Científico. 23 ed. São Paulo: Cortez, 2007.

Recebido em: 25/04/2020

Aceite em: 15/06/2020 